\title{
Knowledge of Hypertension and Compliance with Therapy Among Hypertensive Patients in the Bamenda Health District of Cameroon: A Cross-sectional Study
}

Bentley Mbekwa Akoko · Peter Nde Fon · Roland Cheofor Ngu •

Kathleen Blackett Ngu

Received: November 15, 2016 / Published online: December 29, 2016

(C) The Author(s) 2016. This article is published with open access at Springerlink.com

\section{ABSTRACT}

Introduction: The prevalence of hypertension has continued to increase and is now a great burden for health care providers. Obtaining information on the factors affecting compliance to antihypertensive drugs is thus important. The aim of this study was to assess knowledge of hypertension and to determine factors affecting the compliance of hypertensive patients to their antihypertensive drugs.

Enhanced content To view enhanced content for this article go to www.medengine.com/Redeem/ EC47F0601CC1A059.

B. M. Akoko - P. N. Fon

Faculty of Health Sciences, University of Buea, Buea, Cameroon

B. M. Akoko · R. C. Ngu

Human Health and Disease Connection (2HD)

Research Group, Douala, Cameroon

R. C. Ngu $(\bowtie)$

Mboppi Baptist Hospital Douala, Douala, Cameroon e-mail: rolinaro@gmail.com

R. C. Ngu

Medical Doctors (MD) Research Group, Douala,

Cameroon

K. B. Ngu

Faculty of Medicine and Biomedical Sciences,

University of Yaounde I, Yaounde, Cameroon
Methods: This was a cross-sectional study involving 221 hypertensive patients in the Bamenda Health District. Validated questionnaires were used. From December 2014 to March 2015, knowledge of hypertension was assessed using a 15-item scale, while compliance was assessed using the 8-item Morisky Medication Adherence Scale. Statistical analysis was performed using SPSS version 20.

Results: $14.0 \%, \quad 53.4 \%$, and $32.6 \%$ of participants had adequate, average, and poor knowledge of hypertension, respectively. The antihypertensive compliance rate was $43.9 \%$. Independent predictors of noncompliance were forgetfulness $\quad(\mathrm{OR}=0.011, \quad 95 \%$ $\mathrm{CI}=0.002-0.063)$, lack of motivation due to the incurable nature of the disease $(\mathrm{OR}=0.068$, $95 \% \mathrm{CI}=0.017-0.274)$, and lack of symptoms of the disease $(\mathrm{OR}=0.019, \quad 95 \%$ $\mathrm{CI}=0.02-0.23)$. There was a significant association between compliance and blood pressure control $(p<0.001)$.

Conclusion: Knowledge of hypertension was poor. Compliance rate to treatment was low. Some medication-related, patient attitude, and health care provider factors affected 
compliance. Knowledge positively affected compliance, and good compliance was associated with good blood pressure control. Emphasis should be placed on patient education and reminders to patients to take their drugs.

Keywords: Antihypertensive drugs; Compliance; Hypertension; Knowledge

\section{INTRODUCTION}

Hypertension is a chronic disease characterized by elevation of blood pressure. Medication compliance refers to the act of conforming to the recommendations made by the provider with respect to the timing, dosage, and frequency of medication taking. It is measured over a period of time [1].

In 2008, 40\% of adults worldwide aged 25 and above had been diagnosed with hypertension, and the number of people living with hypertension stood at 1 billion [2]. Hypertension is a major health problem in Cameroon. In 2003, in a study of a population of 10,011 , the prevalence was reported as $24.6 \%$ [3]: $25.6 \%$ in males and $23.1 \%$ in females. Previously considered a disease of the developed world, hypertension is occurring with increasing frequency in developing countries. This increasing prevalence of hypertension has been attributed to increased urbanization and westernization of lifestyles, with a higher prevalence found in the urban as opposed to rural areas [4]. In addition, the prevalence of hypertension is expected to continue to increase globally [5]. The number of adults with hypertension in 2025 is predicted to increase by about $60 \%$, to a total of 1.56 billion.

The prevalence of hypertension is also increasing in Cameroon, as seen from a study assessing changes in blood pressure values over a 10-year period between 1994 and 2003 [6]. The study revealed an increase in mean blood pressures in rural women (SBP $+18.2 \mathrm{mmHg}$, $\mathrm{DBP}+11.9 \mathrm{mmHg})$ and men (SBP $+18.8 \mathrm{mmHg}$, DBP $+11.6 \mathrm{mmHg}$ ). In the urban areas, SBP increased in women $(+8.1 \mathrm{mmHg}, p<0.001)$ and men $(+6.5 \mathrm{mmHg}, p<0.001)$, while DBP increased only in women $(+3.3 \mathrm{mmHg}$, $p<0.001$ ). There was also a significant (two- to fivefold) increase in the prevalence of hypertension (crude and age-adjusted) in rural and urban men and women over the ten-year period. All of these data indicate that hypertension is currently a big challenge to health workers and will continue to be for some time to come.

Blood pressure control involves the implementation of a number of lifestyle modifications as well as the use of one or more antihypertensive drugs [7]. Lifestyle modifications include (amongst others) adjustment of the diet, cessation of smoking, reduction of alcohol intake, weight reduction or control, increase in physical exercise, and stress management. Although lifestyle modifications are important, patients may also require one or more antihypertensive $\operatorname{drug}(\mathrm{s})$ to achieve effective blood pressure control. These drugs will have to be taken by the patient throughout his/her life [7].

The most common complications of hypertension include stroke (cerebrovascular accident), ischemic heart disease, retinopathy, nephropathy, and peripheral vascular disease [8], which can be prevented or delayed by effective blood pressure control. In a study in Douala (2014), hypertension was found to be the most common risk factor for stroke in patients in Cameroon, with $81.2 \%$ of stroke victims found to have a positive history of hypertension [9]. 
While educating patients is the responsibility of qualified health personnel, compliance to therapy depends on the individual patient. A study carried out in Buea (Cameroon) in 2014 revealed that only $33.3 \%$ of hypertensive patients were complying with their antihypertensive drug therapy [10]. In a resource-poor setting in Nigeria, only $32.1 \%$ of the hypertensive patients showed good compliance [11], whereas in a resource-poor setting in Pakistan, it was $48.3 \%$ [12]. A study performed in 2012 in Cameroon revealed that only $59.9 \%$ of known hypertensive patients were taking antihypertensive drugs, despite being aware of their condition [13]. The reasons for this poor compliance need to be better understood if they are to be modified.

We undertook this study to assess patient knowledge of hypertension in hypertensive patients as well as to determine factors affecting the compliance of these patients with their medication, as this information could help to guide the development of interventions to improve drug adherence facilitating optimization of blood pressure control among patients with hypertension in Cameroon.

\section{METHODS}

\section{Study design and setting}

This was an observational cross-sectional study carried out in the Bamenda Health District of the North West Region of Cameroon over a period of four months (December 2014 to March 2015). This health district has a population of about 336,372 persons according to the 2012 national census. It is one of the 19 health districts of the North West Region and comprises 17 health areas: Nkwen Baptist, Nkwen Urban, Mbatchangwa, Atuakom, Ntambag, Ntamulung, Mulang,
Azire, Alakuma, Bamendakwe, Ndza, Akumlam, Alabukam, Mankon, Alamandum, Nkwen Rural, and Ntankah.

\section{Study Participants and Data Collection}

The sample population comprised hypertensive patients who were aged at least 21 years at diagnosis, were on antihypertensive medications for at least 6 months, and resided in communities in the various health areas in the Bamenda Health District of Cameroon. We excluded hypertensive patients who were not on pharmacologic treatment.

Sensitization of the patients was achieved by making announcements in community group meetings and churches. This made them aware of the study beforehand so as to reduce resistance and hostility towards the interviewer.

A convenient sampling method was used. Health areas in this study were chosen based on ease of access and familiarity to the interviewer.

The minimum sample size was calculated using the formula $s=z^{2}[p(1-p)] / d$, where $s=$ minimum sample size, $z=$ standard normal variate, $p=$ an estimate of the proportion of the patients in the study who complied with their antihypertensive drug regimens, $d=$ sample error to be tolerated, and the confidence interval $=5 \%$. Therefore $d=0.05$, confidence level $=95 \%$. This implies $\quad z$-score $=1.96$. Predicted proportion of the patients who complied with their antihypertensive drug regimens $(p)=13 \%$ (this was the compliance in a similar study in Bangladesh [14]).

A minimum sample size of 174 patients was required, but 221 hypertensive patients were ultimately recruited. Hypertensive patients in various health areas in the Bamenda Health District were then approached so as to include them in the study. 
Structured and validated questionnaires were administered orally by the investigator to persons who consented. The questionnaires were used to obtain information on the sociodemographic status of the participants, to assess knowledge of hypertension, to assess compliance with antihypertensive therapy, and to determine the factors affecting compliance.

Blood pressure was measured twice on the same arm after the participant had rested for $5 \mathrm{~min}$, and the average of both values was considered the blood pressure of the participant.

After data collection, participants were educated on the basics of hypertension and its management, and the correct answers to the section on knowledge were given to the participants. Emphasis was placed on the importance of good antihypertensive drug compliance. Any questions the participants had on hypertension and health in general were answered.

\section{DATA MANAGEMENT AND STATISTICAL ANALYSIS}

The data were collected as stated above and entered into Microsoft Excel 2013. SPSS version 20 was used to analyze the data.

Knowledge of hypertension was assessed on a scale of 15 , based on answers to 15 questions, as shown below (Table 1). The scale was adapted from one used in a similar study in Pakistan to assess knowledge of hypertension [15]. A score of less than 8 represented poor knowledge, a score of 9-12 represented average knowledge, and a score of 13-15 represented adequate knowledge.

To assess the association between knowledge and compliance, participants were grouped into those who had adequate knowledge and those who had inadequate knowledge. Compliance with antihypertensive medication was measured using the 8-item Morisky
Medication Adherence Scale. Compliance was measured on a scale of 8 based on answers to 8 questions. A score of less than 3 represented compliance and a score of 3-8 represented noncompliance.

Blood pressure control was assessed as recommended by Joint National Committee JNC 8 [16], based on the blood pressure reading obtained. Blood pressure <140/ $90 \mathrm{mmHg}$ represented good blood pressure control in patients less than 60 years old, blood pressure $\geq 140 / 90 \mathrm{mmHg}$ represented poor blood pressure control in patients less than 60 years old, blood pressure $<150 / 90 \mathrm{mmHg}$ represented good blood pressure control in patients aged 60 years and above, and blood pressure $\geq 150 / 90 \mathrm{mmHg}$ represented poor pressure control in patients 60 years and above.

Other questions in the questionnaire were used to collect information on sociodemographic factors, medication-related factors, complications, and health care provider factors.

All variables were categorized. Chi-square and Fisher's exact tests were used as tests of statistical significance to examine the relationships between variables. Variables were divided into sociodemographic, medication-related, and health care provider-related factors, and analyzed with compliance as the dependent variable. This was used to determine how these factors affected patient compliance. Multivariate analysis of factors which had a statistically significant association with compliance was done by logistic regression to identify independent predictors of noncompliance. Statistical significance was established at $p<0.05$.

\section{Compliance with Ethics Guidelines}

All procedures followed were in accordance with the ethical standards of the responsible 
Table 1 Knowledge of hypertension questionnaire

\begin{tabular}{|c|c|c|c|c|}
\hline & Question & Yes & No & Don't know \\
\hline 1 & Do you know the value above which blood pressure is described as high? & & & \\
\hline 2 & Elevated blood pressure is called hypertension & & & \\
\hline 3 & $\begin{array}{l}\text { A patient always has symptoms like headache, dizziness and fatigue } \\
\text { each time his/her blood pressure is high }\end{array}$ & & & \\
\hline 4 & Both men and women have equal chances of developing hypertension & & & \\
\hline 5 & Hypertension is a curable condition & & & \\
\hline 6 & The older the person is, the greater their chances of having hypertension & & & \\
\hline 7 & Smoking increases the chances of developing hypertension & & & \\
\hline 8 & Eating fatty foods increases the chances of developing hypertension & & & \\
\hline 9 & Being overweight increases the chances of developing hypertension & & & \\
\hline 10 & Regular physical activity reduces a person's chances of developing hypertension & & & \\
\hline 11 & Eating more salt has no effect on blood pressure & & & \\
\hline 12 & Dietary approaches to reduce hypertension do no good & & & \\
\hline 13 & Red meat is good for control of hypertension & & & \\
\hline 14 & Medication alone can control hypertension & & & \\
\hline 15 & Hypertension can lead to other life-threatening diseases & & & \\
\hline
\end{tabular}

committee on human experimentation (institutional and national) and with the Helsinki Declaration of 1964, as revised in 2013. They were also in accordance with the ethical standards of the Institutional Review Board of the Faculty of Health Sciences, University of Buea, Cameroon.

Informed consent was obtained from all participants before they were included in the study.

\section{RESULTS}

\section{Sociodemographic Characteristics of the Population}

Of the persons approached during data collection, 221 met the inclusion criteria for the study. Of the 221 participants, 98 (44.3\%) were male. Ages of participants ranged from 37 to 86 years, with a mean age of $62.86 \pm 11.4$ years. 147 (66.5\%) reported that they were married, and 96 (43.3\%) were retired. 65 (29.4\%) had received secondary education, as opposed to $64(29 \%)$ who had received no formal education (Table 2).

\section{Knowledge of Hypertension}

Of the 221 participants in this study, 31 (14.1\%) had adequate knowledge of hypertension. 118 (53.4\%) had average knowledge, while 72 $(32.6 \%)$ had poor knowledge of hypertension. The factors which positively affected knowledge of hypertension significantly were male sex, age less than 63 years, and higher level of education (Table 3). 


\section{Compliance with Antihypertensive Medications}

Of the 221 participants in this study, 97 (43.9\%) persons were found to be compliant with their antihypertensive drug treatments, while 124 $(56.1 \%)$ persons were found to be noncompliant. Some medication-related factors, patient factors, and health care

Table 2 Sociodemographic characteristics of the population $(N=221)$

\begin{tabular}{|c|c|c|}
\hline Variable & $\begin{array}{l}\text { Frequency } \\
(N=221)\end{array}$ & $\begin{array}{l}\text { Percentage } \\
(\%)\end{array}$ \\
\hline \multicolumn{3}{|l|}{ Sex } \\
\hline Males & 98 & 44.3 \\
\hline Females & 123 & 55.7 \\
\hline \multicolumn{3}{|l|}{ Age (years) } \\
\hline$<40$ & 2 & 0.9 \\
\hline $40-49$ & 22 & 10.0 \\
\hline $50-59$ & 64 & 29.0 \\
\hline $60-69$ & 63 & 28.5 \\
\hline$\geq 70$ & 70 & 31.7 \\
\hline \multicolumn{3}{|l|}{ Marital status } \\
\hline Married & 147 & 66.5 \\
\hline Widowed & 66 & 29.9 \\
\hline Single & 8 & 3.6 \\
\hline \multicolumn{3}{|c|}{ Educational status } \\
\hline $\begin{array}{l}\text { No formal } \\
\text { education }\end{array}$ & 64 & 29.0 \\
\hline Primary & 40 & 18.1 \\
\hline Secondary & 65 & 29.4 \\
\hline Tertiary & 52 & 23.5 \\
\hline \multicolumn{3}{|c|}{ Occupational status } \\
\hline Employed & 87 & 39.4 \\
\hline Unemployed & 38 & 17.2 \\
\hline Retired & 96 & 43.4 \\
\hline
\end{tabular}

provider-related factors were found to have statistically significant associations with compliance. These are shown in Table 4 . The independent predictors of noncompliance following logistic regression were forgetfulness, lack of motivation due to the incurable nature of the disease, and failure to keep clinic appointments (Table 5).

\section{Compliance and Knowledge of Hypertension}

Of the 31 participants who had adequate knowledge of hypertension, 23 (74.2\%) were compliant while $8(25.8 \%)$ were noncompliant. Of the 190 participants who did not have adequate knowledge of hypertension, 74 (38.9\%) were compliant while 116 (61.1\%) were noncompliant. This association between compliance and knowledge on hypertension was statistically significant $(p<0.001)$.

\section{Blood Pressure Control}

The systolic blood pressure (SBP) of the participants in this study ranged from 103 to $223 \mathrm{mmHg}$, with a mean of $154.29 \pm$ $26.8 \mathrm{mmHg}$. The DBP of the participants ranged from 57 to $160 \mathrm{mmHg}$, with a mean of $90.07 \pm 15.98$.

Ninety-three participants (42.1\%) had good BP control, while 128 (57.9\%) had poor BP control. The factors associated with good BP control are shown in Table 6.

\section{DISCUSSION}

We found that 31 participants (14.0\%) had a knowledge of hypertension which could be considered adequate. 118 participants (53.4\%) had average knowledge and 72 (32.6\%) had poor knowledge of hypertension. This was 
Table 3 Factors affecting knowledge of hypertension

\begin{tabular}{|c|c|c|c|c|}
\hline \multirow[t]{2}{*}{ Variables } & \multicolumn{3}{|c|}{ Frequency (percentage) } & \multirow[t]{2}{*}{$P$ value } \\
\hline & Poor & Average & Adequate & \\
\hline \multicolumn{5}{|l|}{ Gender } \\
\hline Male & $24(24.5 \%)$ & $58(59.2 \%)$ & $16(16.3 \%)$ & \multirow[t]{2}{*}{$0.036^{*}$} \\
\hline Female & $48(39.0 \%)$ & $60(48.8 \%)$ & $15(12.2 \%)$ & \\
\hline \multicolumn{5}{|l|}{ Age (years) } \\
\hline$<63$ & $12(11.0 \%)$ & $78(71.6 \%)$ & $19(17.4 \%)$ & \multirow[t]{2}{*}{$<0.001^{*}$} \\
\hline$\geq 63$ & $60(53.6 \%)$ & $40(35.7 \%)$ & $12(10.7 \%)$ & \\
\hline \multicolumn{5}{|l|}{ Educational status } \\
\hline No formal education & $52(81.2 \%)$ & $12(18.8 \%)$ & $0(0.0 \%)$ & \multirow[t]{4}{*}{$<0.001^{*}$} \\
\hline Primary & $10(25.0 \%)$ & $30(75.0 \%)$ & $0(0.0 \%)$ & \\
\hline Secondary & $8(12.3 \%)$ & $48(73.8 \%)$ & $9(13.9 \%)$ & \\
\hline Tertiary & $2(3.9 \%)$ & $28(53.8 \%)$ & $22(42.3 \%)$ & \\
\hline \multicolumn{5}{|l|}{ Clinic attendance } \\
\hline Keep clinic appointments & $36(30.3 \%)$ & $60(50.4 \%)$ & $23(19.3 \%)$ & \multirow[t]{2}{*}{0.063} \\
\hline Do not keep clinic appointments & $36(30.3 \%)$ & $58(56.9 \%)$ & $8(7.8 \%)$ & \\
\hline
\end{tabular}

* Statistically significant

similar to knowledge levels observed in Quetta, Pakistan, in which $37.9 \%$ of participants had poor knowledge, $61.3 \%$ had average knowledge, and only $0.8 \%$ had adequate knowledge of hypertension [15]. In Ido-Ekiti, Nigeria, less than half of participants $(47.1 \%)$ had good knowledge of hypertension [11]. These were however lower than values obtained in North Carolina, where $78 \%$ of participants had a good knowledge of hypertension [17].

The compliance rate among participants in our study was $43.9 \%$, indicating that slightly less than half of the participants were compliant with their antihypertensive medications. This rate is similar to those observed in studies in Shiraz, Iran (39.6\%) [18], Malaysia (44.2\%) [19], Maringa, Brazil (46\%) [20], and Abbottabad, Pakistan (48.3\%) [12]. These countries with similar compliance rates are all developing countries. Health care systems are not the best in these countries, and when coupled with patient factors or the patients' attitude towards health, adherence rates are likely to be low. The compliance rate seen in the present work was lower than the corresponding rates observed in Ethiopia (64.6\%) [21] and Idikan (51\%) [22]. It was also lower than the range of rates, 50-70\%, obtained by WHO from a review of various studies in different countries [23]. The compliance rate in our study was higher than the $33.3 \%$ compliance rate obtained in Buea [10] and the $32.1 \%$ compliance rate obtained in Ido-Ekiti [11].

Females were slightly more compliant than males. This difference was not statistically significant. A similar result was noted in studies in Maiduguri [24] and the DR Congo [25], in which no statistically significant 
Table 4 Factors affecting good compliance with antihypertensive medications

\begin{tabular}{|c|c|c|c|c|}
\hline Variables & $\begin{array}{l}\text { Frequency } \\
\text { (compliant } \\
\text { participants) }\end{array}$ & $\begin{array}{l}\text { Percentage } \\
\text { (compliant } \\
\text { participants) }\end{array}$ & $\begin{array}{l}\text { Odds ratio } \\
(95 \% \text { CI })\end{array}$ & $P$ value \\
\hline \multicolumn{5}{|l|}{ Sociodemographic factors } \\
\hline \multicolumn{5}{|l|}{ Gender } \\
\hline Male & 38 & 38.8 & $0.808(0.593-1.102)$ & 0.171 \\
\hline Female & 59 & 48.0 & & \\
\hline \multicolumn{5}{|l|}{ Age (years) } \\
\hline Less than 63 & 45 & 41.3 & $0.889(0.659-1.200)$ & 0.441 \\
\hline 63 and above & 52 & 46.4 & & \\
\hline \multicolumn{5}{|l|}{ Marital status } \\
\hline Married & 61 & 41.5 & $0.853(0.630-1.155)$ & 0.312 \\
\hline Widowed/single & 36 & 48.6 & & \\
\hline \multicolumn{5}{|l|}{ Educational status } \\
\hline No formal education & 28 & 43.8 & $0.995(0.716-1.384)$ & 0.067 \\
\hline At least primary & 69 & 43.9 & & \\
\hline \multicolumn{5}{|l|}{ Employment status } \\
\hline Employed & 37 & 42.5 & $0.950(0.698-1.293)$ & 0.742 \\
\hline Unemployed/retired & 60 & 44.8 & & \\
\hline \multicolumn{5}{|l|}{ Medication-related factors } \\
\hline \multicolumn{5}{|l|}{ Number of drugs } \\
\hline One drug & 35 & 41.2 & $0.903(0.660-1.236)$ & 0.520 \\
\hline More than one & 62 & 45.6 & & \\
\hline \multicolumn{5}{|l|}{ Belief in drug efficacy } \\
\hline Yes & 95 & 47.7 & $0.190(0.050-0.720)$ & $0.001^{*}$ \\
\hline No & 2 & 9.1 & & \\
\hline \multicolumn{5}{|l|}{ Cost of medications } \\
\hline Affordable & 69 & 59.0 & $2.190(1.542-3.111)$ & $<0.001^{*}$ \\
\hline Expensive & 28 & 26.9 & & \\
\hline \multicolumn{5}{|l|}{ Drug availability } \\
\hline Readily available & 97 & 46.4 & - & $0.002^{*}$ \\
\hline Not readily available & 0 & 0.0 & & \\
\hline Side effects & & & & \\
\hline
\end{tabular}


Table 4 continued

\begin{tabular}{|c|c|c|c|c|}
\hline Variables & $\begin{array}{l}\text { Frequency } \\
\text { (compliant } \\
\text { participants) }\end{array}$ & $\begin{array}{l}\text { Percentage } \\
\text { (compliant } \\
\text { participants) }\end{array}$ & $\begin{array}{l}\text { Odds ratio } \\
(95 \% \mathrm{CI})\end{array}$ & $P$ value \\
\hline Yes & 6 & 21.4 & $2.200(1.066-4.542)$ & $0.010^{*}$ \\
\hline No & 91 & 47.2 & & \\
\hline \multicolumn{5}{|l|}{ Patient factors } \\
\hline \multicolumn{5}{|c|}{ Regular clinic attendance } \\
\hline Yes & 81 & 68.1 & $0.230(0.145-0.367)$ & $<0.001^{*}$ \\
\hline No & 16 & 15.7 & & \\
\hline \multicolumn{5}{|l|}{ Forgetfulness } \\
\hline Never forget & 79 & 90.8 & $6.760(4.375-10.444)$ & $<0.001^{*}$ \\
\hline Sometimes forget & 18 & 13.4 & & \\
\hline \multicolumn{5}{|c|}{ Use of traditional medicine } \\
\hline Yes & 8 & 13.8 & $3.959(2.049-7.647)$ & $<0.001^{*}$ \\
\hline No & 89 & 54.6 & & \\
\hline \multicolumn{5}{|c|}{ Lack of motivation due to incurable nature of disease } \\
\hline Yes & 14 & 13.2 & $5.465(3.311-9.019)$ & $<0.001^{*}$ \\
\hline No & 83 & 72.2 & & \\
\hline \multicolumn{5}{|c|}{ Stop medications when feeling well } \\
\hline Yes & 4 & 5.4 & $11.704(4.477-30.6)$ & $<0.001^{*}$ \\
\hline No & 93 & 63.3 & & \\
\hline
\end{tabular}

* Statistically significant

association between gender and compliance was observed. However, in Dar es Salaam, there was a statistically significant difference, with females found to be more compliant than males [26]. Contrarily, in Taiwan, males were significantly more compliant than females [27].

There was no significant association between age and compliance. This was similar to results of studies done in Ethiopia [21] and Lusaka [28], where there was also no significant association. This was, however, contrary to findings in the DR Congo [25] and Shiraz, Iran [18], in which there was a statistically significant association, with older participants being more compliant than younger ones.

We found no significant association between compliance and marital status. Similar results were obtained in Dar es Salaam [26] and Shiraz, Iran [18]. This result was, however, contrary to findings in Maiduguri [24], in which married participants were found to be significantly more compliant than single participants.

Educational status had no significant association with compliance. This was similar to findings in Dar es Salaam [26] and Maiduguri [24]. 
Table 5 Independent predictors of good compliance to antihypertensive medication

\begin{tabular}{lllr}
\hline Factor & Adjusted odds ratio & $\mathbf{9 5 \%}$ Confidence interval & $\boldsymbol{p}$ value \\
\hline Knowledge of hypertension & 0.694 & $0.113-4.252$ & 0.693 \\
Medication-related factors & & & 0.286 \\
Belief in drug efficacy & 5.497 & $0.240-126.045$ & 0.692 \\
Medication cost & 0.745 & $0.174-3.187$ & 0.998 \\
Drug availability & - & - & 0.290 \\
Side effects & 0.321 & $0.039-2.632$ & \\
Patient attitude/factors & & & $<\mathbf{0 . 0 0 1}^{*}$ \\
Forgetfulness & 0.011 & $0.002-0.063$ & 0.183 \\
Clinic attendance & 2.842 & $0.611-13.216$ & 0.755 \\
Traditional medicine & 1.376 & $0.185-10.226$ & $<\mathbf{0 . 0 0 1}^{*}$ \\
Lack of motivation due to incurable nature of disease & 0.068 & $0.017-0.274$ & $\mathbf{0 . 0 2 0}^{*}$ \\
Asymptomatic nature of disease & 0.019 & $0.02-0.231$ & \\
Health care provider factor & & & 0.184 \\
Condition explanation & 3.221 & $0.574-18.089$ & \\
\hline
\end{tabular}

* Statistically significant

There was no significant association between compliance and occupational status. Participants in active employment were not more or less compliant than those who were not. This was similar to findings in Taiwan [27] and DR Congo [25].

There was no significant association between the number of antihypertensive drugs the participant was taking and compliance with treatment. This was similar to findings in Taiwan [27]. A controlled trial done on hypertensive patients in Japan also supported this [29]. This was contrary to findings in Buea [10], where participants on a single drug were significantly more compliant than those on multiple drugs. The reverse was true in Maiduguri [24] and Lusaka [28], where participants on more than one drug were significantly more compliant.
Participants who believed in the efficacy of the drugs they were taking were more compliant than those who did not believe in the efficacy of the drugs. This difference was statistically significant. This was in accordance with findings in Shiraz, Iran [18].

Participants who found the drugs to be affordable were more compliant than those who found the drugs expensive. This difference was statistically significant. This was similar to findings in Maiduguri [24], the DR Congo [25], and India [30].

The participants who reported that their drugs were not readily available were significantly less compliant. This was similar to findings in Ido-Ekiti [11] and Kuwait [31]. Patients who could not get the drugs they had been prescribed were less likely to be compliant because, even if they had the will, they did not 
Table 6 Factors associated with good blood pressure control

\begin{tabular}{|c|c|c|c|c|}
\hline Variables & Frequency & Percentage & Odds ratio $(95 \% \mathrm{CI})$ & $P$ value \\
\hline \multicolumn{5}{|l|}{ Gender } \\
\hline Male & 34 & 34.7 & $0.723(0.521-1.004)$ & $0.047^{*}$ \\
\hline Female & 59 & 48.0 & & \\
\hline \multicolumn{5}{|l|}{ Age (years) } \\
\hline Less than 63 & 37 & 33.9 & $0.679(0.493-0.936)$ & $0.016^{*}$ \\
\hline 63 and above & 56 & 50.0 & & \\
\hline \multicolumn{5}{|c|}{ Alcohol consumption } \\
\hline Yes & 44 & 31.9 & $1.852(1.368-2.506)$ & $<0.001^{*}$ \\
\hline No & 49 & 59.0 & & \\
\hline \multicolumn{5}{|l|}{ Smoking } \\
\hline Yes & 0 & 0.0 & - & $0.014^{*}$ \\
\hline No & 93 & 43.7 & & \\
\hline \multicolumn{5}{|l|}{ Compliance } \\
\hline Compliant & 71 & 73.2 & $4.126(2.772-6.140)$ & $<0.001^{*}$ \\
\hline Noncompliant & 22 & 17.7 & & \\
\hline
\end{tabular}

* Statistically significant

have the drugs, preventing them from taking their medications as prescribed.

Participants who reported side effects of their drugs were significantly less compliant than those who had never experienced any side effects. This was similar to findings in Lusaka [28] and Idikan [22]. People who experience unwanted effects after taking a drug are more likely to stop taking the drug, resulting in poor compliance.

Some participants never forgot to take their medications. Others sometimes forgot and were less compliant. This difference was statistically significant. Similar findings were obtained in Idikan [22] and Kuwait [31].

There was a statistically significant difference in compliance between participants who regularly kept clinic appointments and those who did not keep appointments. Those who kept clinic appointments were more compliant. This was similar to findings in Lusaka [28] and Mahe in the Seychelles [32].

There was a statistically significant difference in compliance between participants who used traditional medicine to treat their hypertension and those who did not. Those who did not use traditional medicine were more compliant. Similar findings were obtained in Ido-Ekiti [11] and Dar es Salaam [26]. People who tend to use traditional medicine generally believe that the traditional treatment is just as, if not more, effective than the medical treatment. There is therefore competition between the two treatment options, leading to reduced compliance with medical treatment.

Participants who reported a lack of motivation to take their drugs due to the incurable nature of hypertension were less 
compliant than those who had no motivational problems. This association was statistically significant. This was similar to findings in Idikan [22] and Dar es Salaam [26].

Participants who stopped taking their drugs because they felt better or had no symptoms were less compliant than those who did not stop. This association was statistically significant. This is similar to findings in Maiduguri [24] and India [30]. Hypertension usually does not present with any symptoms. Therefore patients who rely on symptoms to take their medications are likely to be noncompliant, as they will certainly skip several doses of treatment when they feel well. The gravity of this is also seen in another study done in Nigeria, where as many as $58.3 \%$ of the participants believed that antihypertensive drugs should only be used when there are symptoms [33].

There was no significant association between compliance and complications. Participants who had experienced at least one complication of hypertension were not more or less likely to be compliant than those who had never experienced a complication. This is similar to what was obtained in Buea [10]. Our findings were contrary to findings in the DR Congo [25] and Shiraz, Iran [18], where patients who had experienced at least one complication were more likely to be compliant than those who had never experienced any complication.

Among the participants who regularly kept clinic appointments, there was no statistically significant association between compliance and confidence in the attending health care personnel.

Participants who were satisfied with how much health care personnel told them about hypertension were more compliant than those who felt they were not told enough about the disease. This relationship was statistically significant. This is similar to what was observed in Lusaka [28]. Patients who are satisfied with what they are told with respect to management will feel more involved in the management process and will be more likely to play their role, which is compliance with the treatment.

There was a statistically significant association between knowledge of hypertension and compliance with treatment. Participants who had adequate knowledge of hypertension were more compliant than those who did not. This was similar to findings in Ido-Ekiti [11] and India [30]. Patients who have more knowledge of hypertension as a whole will have better understanding of the disease. They will therefore better understand important aspects of the disease such as its asymptomatic nature and the need for long-term treatment. They are therefore more likely to be compliant. This was, however, contrary to what was found in Quetta, Pakistan (Quetta, Pakistan), where there was an inverse relationship between knowledge and compliance [15].

$42.1 \%$ of participants had controlled BP. This was similar to the BP control rate of $36.6 \%$ obtained in Ethiopia. This was higher than the BP control rates of $21.3 \%$ obtained in Buea [10] and $29.4 \%$ obtained in the DR Congo [25]. It was also higher than the BP control rate of $24.5 \%$ obtained from a study involving several major cities in Cameroon [13]. This is probably because in those studies with lower BP control rates, good $\mathrm{BP}$ control was considered to be $\mathrm{BP}<140 / 90 \mathrm{mmHg}$. In our study, this was the cutoff point only for participants less than 60 years old. In participants aged 60 years and older, BP control was considered good if BP was less than 150/90 mmHg. This is in accordance with the most recent recommendations by JNC [16]. The higher BP control rates can also be explained by the fact that our compliance rate 
of $43.9 \%$ was higher than the compliance rates of $33.3 \%$ and $21.2 \%$ obtained in Buea and the DR Congo, respectively [10, 25]. All of those were in line with a systematic review of several studies done across Africa, which concluded that the general rate of BP control is low throughout the continent [34].

There was a statistically significant association between compliance and BP control. Patients who were compliant were more likely to have good BP control than those who were noncompliant. This was similar to findings in Buea [10], Kuwait [31], Mahe in the Seychelles [32], and India [30]. The aim of taking medications is to achieve a target $\mathrm{BP}$ so as to have good BP control. Good compliance with treatment will therefore lead to good BP control.

\section{Limitations}

Our study had a small sample size of 221 participants. A larger sample size was difficult to realize due to the fact that we carried out a community-based study and had the difficult task of moving around in communities actively searching for hypertensive patients on antihypertensive medications. We also used a self-report method to assess compliance to treatment, which is an indirect method. While a self-report method was the most feasible method to use in our setting, it is not as accurate as direct methods of assessing compliance.

\section{CONCLUSION}

The knowledge of hypertension among hypertensive patients in Bamenda Health District was poor. Less than half of the patients suffering from hypertension knew enough about the disease, with only $14 \%$ of participants having adequate knowledge.
The level of compliance with antihypertensive drugs was poor, with only $43.9 \%$ of participants showing good compliance. There were several reasons for poor compliance in the Bamenda Health District: medication-related factors, patient attitude/factors, and a health care provider factor. No sociodemographic factor significantly affected compliance with treatment. The independent predictors of noncompliance following logistic regression were forgetfulness, lack of motivation due to the incurable nature of the disease, and asymptomatic nature of the disease.

Knowledge of hypertension positively affected compliance with antihypertensive medications. Participants who knew more about the disease were more compliant.

BP control was poor, with less than half of the participants (42.1\%) having good BP control. Compliance with treatment positively affected BP control, as participants who were compliant with treatment were more likely to have good BP control.

\section{ACKNOWLEDGEMENTS}

The authors thank all study participants for choosing to be part of this study. No funding or sponsorship was received for this study or the publication of this article.

All named authors meet the International Committee of Medical Journal Editors (ICMJE) criteria for authorship for this manuscript, take responsibility for the integrity of the work as a whole, and have given the final approval for the version to be published.

Disclosures. Bentley Mbekwa Akoko, Peter Nde Fon, Roland Cheofor Ngu, and Kathleen Blackett Ngu have nothing to disclose. 
Compliance with ethics guidelines. All procedures followed were in accordance with the ethical standards of the responsible committee on human experimentation (institutional and national) and with the Helsinki Declaration of 1964, as revised in 2013. They were also in accordance with the ethical standards of the Institutional Review Board of the Faculty of Health Sciences, University of Buea, Cameroon. Informed consent was obtained from all participants before they were included in the study.

Open Access. This article is distributed under the terms of the Creative Commons Attribution-NonCommercial 4.0 International License (http://creativecommons.org/licenses/ by-nc/4.0/), which permits any noncommercial use, distribution, and reproduction in any medium, provided you give appropriate credit to the original author(s) and the source, provide a link to the Creative Commons license, and indicate if changes were made.

\section{REFERENCES}

1. Cramer JA, Roy A, Burrell A, Fairchild CJ, Fuldeore MJ, Ollendorf DA, et al. Medication compliance and persistence: terminology and definitions. Value Health. 2008;11(1):44-7 (Epub Feb 02, 2008).

2. World Health Organization. Global status report on noncommunicable diseases 2010. Geneva: World Health Organization; 2011. pp. 164, ix.

3. Kamadjeu RM, Edwards R, Atanga JS, Unwin N, Kiawi EC, Mbanya JC. Prevalence, awareness and management of hypertension in Cameroon: findings of the 2003 Cameroon Burden of Diabetes Baseline Survey. J Hum Hypertens. 2006;20(1):91-2 (Epub Sept 16, 2005).

4. Ibrahim MM, Damasceno A. Hypertension in developing countries. Lancet. 2012;380(9841):611-9 (Epub Aug 14, 2012).

5. Kearney PM, Whelton M, Reynolds K, Muntner P, Whelton PK, He J. Global burden of hypertension: analysis of worldwide data. Lancet. 2005;365(9455):217-23 (Epub Jan 18, 2005).

6. Fezeu L, Kengne AP, Balkau B, Awah PK, Mbanya JC. Ten-year change in blood pressure levels and prevalence of hypertension in urban and rural Cameroon. J Epidemiol Community Health. 2010;64(4):360-5 (Epub Aug 21, 2009).

7. Mancia G, Fagard R, Narkiewicz K et al. ESH/ESC Guidelines for the Management of Arterial Hypertension. Blood Press. 2013;22(4):193-278 (Epub June 20, 2013).

8. Law M, Wald N, Morris J. Lowering blood pressure to prevent myocardial infarction and stroke: a new preventive strategy. Health Technol Assess. 2003;7(31):1-94 (Epub Nov 08, 2003).

9. Mapoure YN, Kuate C, Tchaleu CB, Ngahane HBM, Mounjouopou GN, Hamadou Ba, et al. Stroke epidemiology in Douala: three years prospective study in a teaching hospital in Cameroon. World J Neurosci. 2014;4:406-14 (Epub Nov, 2014).

10. Adidja NM. Adherence to anti-hypertensive treatment in the Buea Health District-a community based study. MD thesis. Buea: University of Buea; 2014.

11. Busari OA, Olanrewaju TO, Desalu OO, Opadijo OG, Jimoh AK, Agboola SM, Busari OE, Olalekan O. Impact of patients' knowledge, attitude and practices on hypertension on compliance with antihypertensive drugs in a resource-poor setting. TAF Prev Med Bull. 2010; 9(2):87-92.

12. Ahmed N, Abdul Khaliq M, Shah SH, Anwar W. Compliance to antihypertensive drugs, salt restriction, exercise and control of systemic hypertension in hypertensive patients at Abbottabad. J Ayub Med Coll Abbottabad. 2008;20(2):66-9 (Epub April 24, 2009).

13. Dzudie A, Kengne AP, Muna WF, Ba H, Menanga A, Kouam Kouam C, et al. Prevalence, awareness, treatment and control of hypertension in a self-selected sub-Saharan African urban population: a cross-sectional study. BMJ Open. 2012;2(4) (Epub Aug 28, 2012).

14. Ekram ARMS, Hussain SM, Boonshuyar C. Preliminary report on non-adherence to antihypertensive treatment in essential hypertensive patients: a community based survey. J Teach Assoc RMC Rajshahi. 2008;21(2).

15. Saleem F, Hassali M, Shafie A, Awad A, Bashir S. Association between knowledge and drug adherence in patients with hypertension in Quetta, Pakistan. Trop J Pharm Res. 2011;10(2):125. 
16. James PA, Oparil S, Carter BL, Cushman WC, Dennison-Himmelfarb C, Handler J, et al. 2014 evidence-based guideline for the management of high blood pressure in adults: report from the panel members appointed to the Eighth Joint National Committee (JNC 8). J Am Med Assoc. 2014;311(5):507-20 (Epub Dec 20, 2013).

17. Viera AJ, Cohen LW, Mitchell CM, Sloane PD. High blood pressure knowledge among primary care patients with known hypertension: a North Carolina Family Medicine Research Network (NC-FM-RN) study. J Am Board Family Med. 2008;21(4):300-8 (Epub Jul 10, 2008).

18. Hadi N, Rostami-Gooran N. Determinant factors of medication compliance in hypertensive patients of Shiraz, Iran. Arch Iran Med. 2004;7(4):292-6.

19. Hassan NB, Hasanah CI, Foong K, Naing L, Awang $\mathrm{R}$, Ismail SB, et al. Identification of psychosocial factors of noncompliance in hypertensive patients. J Hum Hypertens. 2006;20(1):23-9 (Epub Sept 24, 2005).

20. Demoner MS, Ramos ERP, Pereira ER. Factors associated with adherence to antihypertensive treatment in a primary care unit. Acta Paulista Enfermagem. 2012;25(S1):27-34. (Epub June 07, 2012).

21. Ambaw AD, Alemie GA, W/Yohannes SM, Mengesha ZB. Adherence to antihypertensive treatment and associated factors among patients on follow up at University of Gondar Hospital, Northwest Ethiopia. BMC Public Health. 2012;12:282 (Epub April 12, 2012).

22. Osamor PE, Owumi BE. Factors associated with treatment compliance in hypertension in southwest Nigeria. J Health Popul Nutr. 2011;29(6):619-28 (Epub Jan 31, 2012).

23. World Health Organization, Sabaté E. Adherence to long-term therapies: evidence for action. Geneva: World Health Organization; 2003. pp. 198, xv.

24. Okoro RN, Ngong CK. Assessment of patient's antihypertensive medication adherence level in non-comorbid hypertension in a tertiary hospital in Nigeria. Int J Pharm Biomed Res. 2012;3(2):47-54 (Epub June 12, 2012).

25. Ikama MS, Nsitou BM, Loumouamou M, Kimbally-Kaky G, Nkoua JL. Drug compliance and its factors in a group of hypertensive Congolese. Pan Afr Med J. 2013;15:121 (Epub Nov 21, 2013).

26. Joho AA. Factors affecting treatment compliance among hypertension patients in three district hospitals-Dar es Salaam. Dar es Salaam: Muhimbili University of Health and Allied Sciences; 2012.

27. Lin Y-P, Huang Y-H, Yang Y-C, Wu J-S, Chang C-J, $\mathrm{Lu}$ F-H. Adherence to antihypertensive medications among the elderly: a community-based survey in Tainan City, Southern Taiwan. Taiwan Geriatric Gerontol. 1995;2(3):176-189.

28. Mweene MD, Banda J, Andrews B, Mweene MM, Lakhi S. Factors associated with poor medication adherence in hypertensive patients in Lusaka, Zambia. Afr J Online. 2010;37(4):252-261.

29. Matsumura K, Arima H, Tominaga M, Ohtsubo T, Sasaguri T, Fujii K, et al. Does a combination pill of antihypertensive drugs improve medication adherence in Japanese? A randomized controlled trial. Off J Jpn Circ Soc. 2012;76(6):1415-22 (Epub Mar 27, 2012).

30. Susan R, Anu K, Achu T, Soumya G, Vijayakumar K, Anish T. Antihypertensive drug compliance across clinic and community settings, in Thiruvananthapuram, South India. Health Sci. 2012;1(3):JS002A.

31. Al-Mehza AM, Al-Muhailije FA, Khalfan MM, Al-Yahya AA. Drug compliance among hypertensive patients; an area based study. Eur J Gen Med. 2009;6(1):6-10.

32. Bovet P, Burnier M, Madeleine G, Waeber B, Paccaud F. Monitoring one-year compliance to antihypertension medication in the Seychelles. Bull World Health Organ. 2002;80(1):33-9 (Epub March 9, 2002).

33. Familoni BO, Ogun SA, Aina AO. Knowledge and awareness of hypertension among patients with systemic hypertension. J Natl Med Assoc. 2004;96(5):620-4 (Epub May 27, 2004).

34. Kayima J, Wanyenze RK, Katamba A, Leontsini E, Nuwaha F. Hypertension awareness, treatment and control in Africa: a systematic review. BMC Cardiovasc Disord. 2013;13:54 (Epub Aug 07, 2013. 